\title{
MAPPING THE VARIOUS FACTORS PLAYING A ROLE IN BIBLICAL INTERPRETATION
}

\author{
Louis C Jonker \\ Department of Old and New Testament \\ Stellenbosch University
}

\section{Introduction}

Biblical interpretation (as is the case with any interpretation ${ }^{1}$ ) is a multidimensional ${ }^{2}$ and dynamic process. This means that various factors interact in the interpretation process. Interpreters are normally aware that some of these factors play a role, but there are often many factors of which interpreters are not aware of during the process of interpretation. These factors influence the process unconsciously.

In order to venture the description of the process of interpretation in Bible study groups, one has to consciously reflect on these factors. If hermeneutics is understood to be the theoretical reflection on interpretation, this discipline should assist in identifying these factors. Without claiming comprehensiveness, a list ${ }^{3}$ of factors that possibly influence the process of Biblical interpretation in Bible study groups is presented in the next subsection.

However, listing, or even categorizing, these factors will not provide an adequate framework for describing the dynamics of the interpretation process. Hermeneutics should also assist in the description of the interaction that takes place among these factors. Hermeneutical reflection should therefore go one step further, namely to plot these factors on an "interpretation map". Of course, there is not only one "correct" map to be drawn. As it was already indicated in the publication Fishing for Jonah": "Such a map can never include all the data, but can at least try to show where certain beacons stand in relation to one another" (p. 270). Various attempts at drawing a map will therefore be listed in the second subsection.

\section{Some factors playing a role in Biblical interpretation}

i. Various sender levels: Each text in the bible originates from somewhere/someone. No text simply appears without an origin. During the different phases of textual production (which, in the case of ancient texts such as that in the Bible, span many centuries) various senders can thus be distinguished. From the phase of oral transmission to the phase of the finalization of written texts, compositions and redactions, a dynamic process of growth takes place ${ }^{5}$. The senders in this dynamic process are e.g. oral tradents, authors, compositors and redactors ${ }^{6}$. Even the translators of the ancient translations of the Bible (e.g. the Greek Septuagint) can be categorized as senders.

ii. Different stages of textual development (oral traditions, written sources, compositions, redactions, canon, textual variations, translations): Closely linked to the previous and

1. Cf. Lawrie's contribution in this volume on the variety of meanings that the term "interpretation" may have.

2. For an in-depth discussion of this term, cf. Jonker, LC (1996).

3. The genre "list" does not propound to argue for or against any of the items in the list. It merely offers a variety of possibilities which have a common denominator, in this case "factors that influence biblical interpretation".

4. Conradie, EM et al (1995).

5. It is particularly the historical-critical methods of tradition history and redaction history that aim to disclose this process of textual formation.

6. Cf. my $(1996,320)$ description of the diachronical and synchronical aspects of the sender. 
the following factors, one could distinguish as a separate factor the different stages of textual development. Biblical texts should not be viewed as a unified one-dimensional block that originated at once at some distant point in the past. Because of the long period of textual growth that produced them, Biblical texts carry the "stigmata" of different periods in time.

iii. The historical, socio-cultural, political, economic, and religious contexts of each sender level: Often (if not always) texts reflect more of the circumstances from which they originate than of the circumstances they describe. It is therefore important to take into consideration all the factors that make up the socio-historical fibre of each sender level. Each sender level can be described with reference to different combinations of these socio-historical factors (with all the values that accompany these factors). These circumstances and values form the background against which the process of textual growth took place. It is particularly the social-scientific approaches to exegesis that focus on this interaction between the biblical texts and the ancient socio-cultural world ${ }^{7}$.

iv. Ideological biases during the process of textual production: The circumstances from which biblical texts originated, as described above, normally generated certain values that people strove for. These values normally corresponded to a certain worldview and a perception of reality. These values, when embedded in some sort of struggle for power or control, lead to ideological biases such as racism, classism, sexism, imperialism and elitism $^{8}$. When texts were (and are!) produced they naturally reflected these ideological biases. Biblical texts are thus not free of "systematically distorted interpretations" (as Habermas has called the result of ideological influence) $)^{9}$.

v. Literary genre: Literary genres are not merely a matter of style. Genres normally tend to evoke certain reactions in the reader/hearer. When the reader/hearer does not identify the genre correctly, it may even lead to wrong questions being posed to that piece of literature, or to an undesired reaction. This, of course, also applies to biblical texts. One encounters in the Bible a great variety of literary genres. Modern readers are well acquainted to some of these genres and they know how to react to them. However, many (if not the majority) of these ancient genres are unknown to modern readers, and can easily be misinterpreted ${ }^{10}$.

vi. Linguistic structure of text: Ferdinand de Saussure's valuable general linguistic distinctions are well-known. Language as a system of signs could be analyzed structurally. The meanings of different signs in a text can be determined only by analyzing the internal relationships within the system of signs. The idea is that a text is never a disorganized collection of words and sentences. The way signs are organized in a text influences the meaning of the text. The question is therefore: how is the meaning of a text expressed in its structure? Within a structuralist approach a distinction is made between the surface structure and the deep structure of a text. The surface structure is the outward syntactical reflection of some inward and deeper-lying thought structure.

7. Cf. Arendse's (in Conradie et al, 1995, 197ff.) description of the renewed interest in socio-historical approaches. He illustrates this approach by referring mainly to the cultural-anthropoligical work of Bruce Malina.

8. Cf. the description of the problem of ambiguity in Conradie et al (1995, 9ff.) and Conradie \& Jonker (2001, 15ff.).

9. Two examples from the Old Testament are described in Jonker, Conradie \& Botha (1997, 31ff.): (i) A comparison is made between Jeremiah's and Ezekiel's views on the temple in which different ideologies can be identified; (ii) With reference to Exum's discussion on Judges 11, it is shown how male-patriarchal values influenced the discription of the death of Jephtah's daughter.

10. Cf. the examples in Chapter 3 of Jonker, Conradie \& Botha $(1997,67 \mathrm{ff}$.$) .$ 
Analysis of the syntactical structure (surface structure) of a text can then lead the reader/hearer to discover the thought structure (deep structure) of the sender(s) ${ }^{11}$.

vii. Semantic structure of text: Language is made up of signs, and different signs have different connotations. These signs occur not only on word level, but also on the level of phrases and sentences. According to De Saussure there are no stable signs. "In each language certain connotations are assigned to a distinctive 'signifier' in a unique and arbitrary way. The connection between a signifier and a signified is entirely coincidental and conventional. It is based on an incidental link between an unlimited stream of signifiers and a similarly undifferentiated stream of meanings"12. This factor confronts the reader/hearer with the ambiguities of language and makes one aware of multiple meaning (polisemy) ${ }^{13}$.

viii. Rhetorical stance/register/mood of text: Although the term rhetoric is used primarily to refer to communication between a speaker and an audience, it can also be used in the study of written communication. In the classical tradition, e.g. in Aristotle's Rhetoric, rhetoric was seen as the art of persuasion in matters about which difference of opinion is possible. In practice, rhetorical criticism emphasizes mainly two factors in the functioning of texts ${ }^{14}$ : Firstly, it can emphasize the main elements in the chain of arguments and the typical rhetorical style of the particular piece. Or it can concentrate on the fine details of the individual strategies in each sentence and on the rhetorical "turns" that go towards building up the persuasive force of the whole.

ix. Rhetorical stylistics of text: In some instances (e.g. in the work of James Muilenburg and his followers) the term "rhetoric" and rhetorical criticism represent and investigate yet another aspect of texts. Muilenburg ${ }^{15}$ suggested that rhetorical criticism would be a corrective to the one-sidedness of form criticism. The latter tends to focus on the general features of the genre of a specific literary unit. In this procedure the unique features of the specific unit disappear into the background. Furthermore, form criticism tends to concentrate on the smaller units that can be identified as "pure genres". The more comprehensive units within which the individual pieces are artistically interwoven then disappear from the view of the critic. Muilenberg's approach thus focuses on the rhetorical stylistics of a text (rhetoric defined here as "fine speech") which can lead the hearer/reader to discover the aim, thrust or line of thought of the sender(s).

$\mathrm{x}$. Narrative structure of text: The study of literature has emphasized that narratives utilize different techniques to tell a story in such a way that the hearers/readers will become involved ${ }^{16}$. The plot line of a narrative, the characterization techniques, the switching of perspectives, etc. lead the hearer/reader to react according to a certain line of tension. In doing so, the hearer/reader is drawn "into" the narrative to become part of the plot, to identify with certain characters, and even to become persuaded to change his/her/their lifestyle, values, etc. This is, of course, also true with regard to Biblical narratives.

11. For a discussion of the theoretical presuppositions of a structuralist approach, as well as an example from the book of Jonah, cf. Conradie et al (1995, 116ff.).

12. Conradie et al $(1995,117)$.

13. Cf. Conradie \& Jonker (2001, 15ff.).

14. Cf. Lawrie's contribution on "Rhetorical criticism" in Conradie et al $(1995,147)$.

15. Cf. Lawrie's description of Muilenberg's approach in Conradie et al $(1995,154)$.

16. For short descriptions of the aspects that play a role in narratives, cf. Jonker (in Conradie et al 1995, 129ff.; 1997, 73ff.), as well as the more thorough discussion in Jonker (1996, 185ff.). 
xi. Intertextuality: No text could be understood in isolation. It always stands in close relationships with other texts, be they written texts (e.g. other texts in the Bible), or texts in the post-modern sense of the word. Since the term text is not limited to written texts in post-modernism, the term intertext enables one to bring into play appropriate signs taken from different areas of human experience. These signs come into play, not as external factors, but as part of textuality which enriches the meaning of the written text. A text is not "there" as an inaccessible, untouchable monument; it is not an enclosed selection of signs but a web, or a differential network, of signs. The meaning and significance of signs are influenced by the similarities to and differences from an infinite number of other signs in other texts. A text is therefore actually an event in which a group of vibrant signs participates in a play of signs and in which, for a short while, the reader is also included ${ }^{17}$.

xii. Textual context: Normally this term refers to the immediate written/literary context in which a text occurs. The literary framework in which a narrative, for example, is being presented (i.e. what comes before and after the narrative), influences the way in which that narrative will be understood by the reader/hearer. In some circles the textual context is also called "co-text" to distinguish it from the context in the world-behindthe-text ${ }^{18}$. If the textual context is ignored, it may lead to distortions in the understanding of a specific text ${ }^{19}$.

xiii. Historical, socio-cultural, political, economic, religious context of each reception level: People in different circumstances interpret the Bible differently ${ }^{20}$. Various variables determine who the readers/hearers are. The following factors could, inter alia, be mentioned: political convictions, socio-economic circumstances, gender, culture, language, educational background and ecclesial/theological tradition. These factors determine which values readers/hearers pursue, and how they regard reality. These values and views on reality form the background against which interpretation takes place ${ }^{21}$.

xiv. Ideological biases during the process of interpretation: In the discussion of the role of ideology in the production of texts above (in iv), it was already mentioned that the above-mentioned values, when embedded in some sort of struggle for power or control, lead to ideological biases such as racism, classism, sexism, imperialism and elitism $^{22}$. Readers/hearers are unable to escape these biases when the read the Bible. However, they can at least become aware of them ${ }^{23}$.

$\mathrm{xv}$. Creative role of the reader/hearer: Interpretation does not boil down to a passive reception of textual stimuli. Texts are often (always?) in desire of closure. There are

17. Conradie (in Conradie et al, 1995, 182ff.) describes the impact of these views in a chapter on "deconstruction" as interpretation strategy. Cf. also my contribution (1999) in which I, with reference to Degenaar's explanation of the terms textuality and intertextuality, argue that communities of faith operate as texts in the process of Biblical interpretation.

18. Cf. e.g. the distinctions made by Robbins (1996).

19. Cf. examples of such distortions in Conradie's discussion of interpretation strategies used by ordinary readers of the Bible (Conradie et al, 1995, 51).

20. Cf. the discussion of the problem of plurality in interpretation in Conradie et al (1995, $7 \mathrm{ff}$.), as well as Lawrie's contribution of the role of the reader in the same publication $(1995,162 \mathrm{ff}$.).

21. Cf. the examples of different interpretations of the same text presented in Jonker, Cornadie \& Botha (1997, 24ff.).

22. Cf. Conradie's discussion of the problem of ambiguity in interpretation in Conradie et al (1995, 9ff.).

23. A variety of ideology-critical approaches to Biblical interpretation, which all arise from a hermeneutics of suspicion, are at the disposal of modern-day exegetes. Cf. e.g. the discussions of Psychoanalytic, Marxist and Feminist approaches in Conradie et al (1995, 211ff.). 
gaps in texts that should be filled in the process of reading. Interpretation is, so to say, a creative process of gap filling (as literary critics such as Iser and Jauss have indicated). This factor emphasizes that meaning is no longer seen as something inherent in texts (whether situated in the world-behind-the-text, or in the text structures itself), but is the creative product of the interaction between readers/hearers and texts ${ }^{24}$.

xvi. Ecclesial tradition of the reader/hearer: The ecclesial tradition of any reader/hearer forms the theological background against which the interpretation of Biblical texts takes place. Different factors play an important role in the formation of such a tradition, e.g. the interpretation of the core gospel, the process of canonization, the creeds, the confessions, the influence of theological schools, as well as the influence of the contemporary church praxis ${ }^{25}$.

xvii. Psychoanalytical disposition of the reader/hearer: The discipline of psychoanalysis makes us aware of the role that psychoanalytical dispositions play in the process of interpretation, and it has drawn attention to the unconscious urges and motivations lying beneath the surface of the ostensibly rational, ordered world of consciousness ${ }^{26}$.

xviii.Wirkungsgeschichte of texts (or: tradition): The German term is used to indicate that interpretation of texts never takes place isolated from previous attempts at interpreting those texts. Interpretation always connects up with already existing interpretations and simultaneously has an innovative effect on the existing tradition of interpretation. The traditioning process is an ongoing event that transcends any individual interpreter. The tradition gains a life and momentum of its own. Each new interpretation is a moment in the traditioning process. The tradition provides an ongoing mediation between past and present ${ }^{27}$.

xix. Configuration of communication process: The elements of sender, medium and receiver do not operate independently in the process of communication. Instead, they form a dynamic system. This, of course, is also applicable to Biblical interpretation as communication. Each unique communication process has a specific structure or compositeness which can be referred to as its synchronical aspect. However, each communication process differs from other communication processes, because its structure or compositeness varies from time to time, and from situation to situation. This variation, which is closely associated with the Wirkungsgeschichte of texts (as discussed above), can be described as the diachronical aspect of the communication process $^{28}$.

\section{Mapping/matrixing/grouping the various factors}

In my article $(1999,79 \mathrm{ff}$.) on the status of communities of faith as texts in the process of Biblical interpretation, I have argued (together with others) that a process of matrixing is inevitable in the process of interpretation. This also applies to all the factors that play a role (as texts) in the process of Biblical interpretation.

24. Cf. Lawrie's discussion of the role of the reader in Biblical interpretation in Conradie et al $(1995,162 \mathrm{ff}$.).

25. For a more elaborate discussion of each of these factors, cf. Conradie in Conradie et al (1995, 25-31).

26. Lawrie in Conradie et al $(1995,214 \mathrm{ff}$.) discusses which influence the psychoanalytical approaches of Freud, Jung and Lacan may have on Biblical intepretation.

27. Cf. the description in Conradie et al $(1995,264)$ of Gadamer's coining of this terminology.

28. Cf. Jonker (1996, 322ff.) for a description of the configuration of the communication process in the context of a multidimensional approach to exegesis. In the next section the terminology synchronical and diachronical will be discussed. 
However, some post-modern scholars would disagree with this statement. In terms of a purely deconstructionist view of intertextuality, one would say that no text has any privilege over against other texts. All texts are equal. As Miscall $(1995,45)$ puts it: “... textual authority and status are always in question since texts are interdependent and use each other. No text is an island." This would mean that no text (or factor in the interpretation process) would have a privileged position with regards to any other text in the all-encompassing network of textuality. What is important are not the participating texts, but their interrelationship, their intertextuality.

In the above-mentioned article I have agreed with Beal (1992, 27-39), Nielsen (1994, $44)^{29}$, Van Wolde $(1990,341-342)^{30}$ and others that such a view would make reading impossible. As Beal $(1992,26)$ puts it: "... no intertextual reading can choose the 'general text' - everything, all at once, everywhere - as its object of interpretation." Or as the oftenquoted Fish $(1980,319)$ has indicated: ".... while relativism is a position one can entertain, it is not a position one can occupy. No one can be a relativist, because no one can achieve the distance from his (sic!) own beliefs and assumptions which would result in their being no more authoritative for him (sic!) than the beliefs and assumptions held by others ..." (his italics). According to Fish, understanding always takes place contextually. Although there is a plurality of meanings, the beliefs and assumptions of the reader/hearer determine which one of these meanings becomes prominent. However, these beliefs and assumptions "are not individual-specific or idiosyncratic, but communal and conventional" $(1980,321)$. Fish therefore introduces the now well-known notion of interpretive communities.

If these qualifications of intertextuality by Beal, Fish and others are true, it then follows that a certain degree of framing, or matrixing (as Voelz (1989 \& 1995) calls it), is inevitable in intertextual interpretation (over-against intertextual theory). To quote from Beal $(1992,28)$ again: "For the practice of intertextual reading, however, as opposed to theories of intertextuality, one must have such lines of delimitation, no matter how arbitrarily they may be set, and no matter how quickly they may be transgressed. ... the practice of intertextual reading must find its place somewhere between the closed structure of a single text (however defined) and the uncontainably surplussive fabric of language (called intertextuality)."Against the background of the above theoretical discussion various attempts at mapping/matrixing/grouping of the factors that play a role in Biblical interpretation will be presented in this subsection. This theoretical background, of course, also prompts us to reconsider the status of our maps. A map is not a replica of reality. Therefore, no map is final or all encompassing. However, maps assist us in the navigation process within reality. This also holds true with regards to the process of Biblical interpretation. The maps presented in this section are all such attempts at matrixing/grouping/mapping the various factors that were mentioned in the previous section.

i. $\quad$ The world behind, inside, in front of (and underneath) the text: Many scholars prefer to distinguish between three "worlds" involved in the process of Biblical

29. Cf. the following statement of Nielsen $(1994,44)$ : "To use a metaphor we might say that a text is always part of an ongoing dialogue between older and younger texts. Our task as exegetes is therefore to try to trace this dialogue - this intertextuality - through history. We are not concerned with just any intertextuality, but with the intertextuality that comes out of the historical situation in which the text was written, used and re-used, and the historical situation in which I live as a scholar and as a person."

30. Van Wolde (1990, 341-342) criticizes views of textuality that either focus exclusively on the object (the written text), or that focus exclusively on the subject (the reader).

31. Although the term "world" suggests a broader understanding of each element of the communication process, this map is closely related to that mentioned in (iv) below. 
interpretation $^{32}$. (a) The world-behind-the-text refers to all the circumstances (i.e. the historical context - not only physical, but also in terms of values, customs, cultural habits, etc.) and hands (be they oral tradents, authors, compositors or redactors) that produced the texts. Not only the history of the events behind the text, but also the history of the text itself is included in this world. However, one should keep in mind that the world-behind-the-text could, in the case of ancient texts, only be known by means of and through the texts. The study of this world thus has an ever-theoretical and speculative nature. (b) The world-inside-the-text refers to those structures (be they grammatical, semantical, syntactical, rhetorical, or narratological) that relate signs to one another in texts. The focus in a study of this world is thus on the text itself. (c) The world-in-front-of-the-text refers to the contemporary contexts in which the texts are being interpreted. The study of this world represents a significant shift in emphasis from the two previously mentioned worlds. Those who study the world-behind-thetext and the world-inside-the-text normally regard meaning as something inherent to texts. Meaning is either seen as something that should be uncovered in the events behind the text, or in the structures of the text itself. However, those who study the world-in-front-of-the-text normally are of the opinion that meaning is not something inherent to texts, but that meaning is creatively produced in the interaction between readers/hearers and texts. (d) Some scholars complement this map with a fourth world, namely the world-underneath-the-text. This addition is an attempt to give account for the ideological biases that play a significant (even determining) role on all levels of textual communication (as discussed in the previous section).

ii. Historical context - text - tradition - suspicion - spiral of interpretation contemporary context: This $\operatorname{map}^{33}$ also makes a tripartite distinction between the historical context, the text and the contemporary context. However, it also elaborates on what happens between the text and the contemporary context during the process of interpretation. Intrinsically it is an attempt to criticize those who want to "jump" the historical gap between the completion of the written texts and the contemporary contexts in which the texts are read/heard. This gap is bridged by a tradition of interpretation that is constituted ecclesially and theologically. Each new act of interpretation also involves other and new filters of suspicion over against the historical context, the text, the tradition and the contemporary context. This results into a never-ending spiral of renewal in interpretation.

iii. Text - Context: The presupposition of this map is that interpretation entails the linking of text and context in some or other way ${ }^{34}$. According to this map the crucial questions is: Is the bridge of interpretation well founded on both sides (text and contemporary context)? And how "strong" is the bridge? The factors that are listed above are thus separated into three groups: those referring to textual matters, those referring to contextual matters, and those referring to the hermeneutical strategies that are utilized to bridge the gap between text and context.

iv. Sender - Medium - Receiver: According to this map the process of interpretation is viewed as a communication process ${ }^{35}$. The most basic description of this communication process is to distinguish between sender, medium, and receiver. This description is often complemented with a distinction of various sender and receiver

32. Cf. e.g. West's contribution (1991) in this regard.

33. Cf. Smit's (1987) use of this map.

34. Cf. e.g. the discussion in Conradie et al (1995, 12ff.) and Conradie \& Jonker (2001, 32ff.).

35. Cf. e.g. Lategan's description (1992, 149ff.). 
levels ${ }^{36}$. Most scholars that use this communication model as a description of the interpretation process, emphasize that the communication process is not a linear or one-dimensional process, but that one should rather perceive the process as being complex and multidimensional. No textual communication is merely a movement from sender to medium to receiver. Each interaction between these communication elements is a dynamic and unique act of communication.

v. Textual production - Textual reception: This map distinguishes between two phases in the process of textual communication. Textual production would then refer to those processes that brought about the ancient texts (initially oral, but later written and canonized). Textual reception would refer to those processes that appropriated these ancient texts for contemporary contexts. Pertaining to textual reception a distinction is often made between textual reception by the first/early readers, and textual reception by contemporary readers. The benefit of this map is that the process of communication is portrayed as a dynamic one. However, some poststructuralists would say that textual reception and textual production should not be regarded as two processes ${ }^{37}$. The reciprocal processes of textual production and textual reception in ancient and contemporary contexts tend to obliterate the boundaries between them. Textual production becomes textual reception, and vice versa. The boundaries between texts and their interpretations become irrelevant ${ }^{38}$.

vi. Centrifugal (deductive) - Centripetal (inductive): This map concerns the priority that is given to certain factors, or the sequence in which they should be taken into account in the interpretation process. A centrifugal (or deductive) approach gives priority to factors pertaining to the text, while a centripetal (or inductive) approach gives priority to factors pertaining to the context (cf. iii above) ${ }^{39}$. However, these two approaches can be distinguished logically, but not temporally. They normally occur simultaneously. The constant interaction between deductive and inductive approaches forms the theoretical backbone of the interpretation model that is proposed in Conradie et al (1995, 35ff.): "Aspects of both approaches are indeed usually present in the concrete act of biblical interpretation. Perhaps the point of departure is not all that crucial. You may start with either the text or the context. It is far more important to maintain the dynamic interplay between the two. This interaction between text and context leads to an ongoing process in which one's pre-understanding of the meaning and implications of the text is continuously revised and refined with respect to both the faithfulness of the interpretation to the text and its relevance with a contemporary context. This constant interaction ... is never stabilized or completed."

vii. Diachronical - Synchronical: This map originates from the distinction Ferdinand de Saussure made in his general linguistic studies. According to De Saussure ${ }^{40}$ a diachronical study is an investigation of the relationship between sequential elements or constructions that cannot be perceived by a common collective consciousness, and which do not form a system. A synchronical study, however, is an investigation of the

36. Cf. e.g. my description (1996, 317ff.) of the synchronical and diachronical aspects of the sender, medium and receiver.

37. Cf. my discussion $(1999,79 f f$.$) .$

38. Cf. Lawrie's contribution earlier in this volume on reading, writing and reinscription.

39. Cf. the discussion of these two approaches, as well as of the problems that are related to each of them, in Conradie et al (1995, 33-35).

40. Cf. my discussion of De Saussure in Jonker $(1986,15 \mathrm{ff}$ ), as well as my implementation of this distinction within the context of a multidimensional exegetical model $(1996,66-70,285-287,315 \mathrm{ff}$.). 
logical and psychological relationships between elements that exist collaterally, which form a system of signs and which can be perceived by a common collective consciousness. A diachronical analysis thus involves temporality, whereas a synchronical study focuses only on the relationship between signs on a given time. This map presupposes that one could approach Biblical texts in the interpretation process either diachronically, or synchronically. However, this distinction often leads to the unsatisfactory situation that either the diachronical, or the synchronical factors of Biblical texts are ignored. Discussions among those who favour this map therefore centre on the questions of priority and the possible integration of these two approaches ${ }^{41}$.

viii. Multidimensional: This map takes its point of departure in the multidimensionality of the interpretation process ${ }^{42}$. It therefore incorporates aspects of more than one of the above-mentioned maps, but also shows how these aspects are related to one another. The main emphasis of this map is its description of the communication process that takes place in interpretation (sender-medium-receiver) not only synchronically, but also diachronically. Each element of the communication process has a synchronical, as well as a diachronical aspect. This also applies to each new configuration of the communication process (cf. the discussion above). The interaction that takes place between sender and medium is described in terms of the synchronical aspect of the sender, while the interaction between receiver and text is described in terms of the synchronical aspect of the receiver. According to this map the factors mentioned above can be grouped multidimensionally. E.g. factor (i) refers to the diachronical aspect of the sender. Factor (iii) refers to the synchronical aspect of the sender. Factors (v)-(x) refer to the synchronical aspect of the medium. Factor (ii) refers to the diachronical aspect of the medium, etc.

ix. Source oriented and discourse oriented: This map which was proposed by Sternberg ${ }^{43}$ suggests two modes of inquiry which are not mutually exclusive, but rather function in close cooperation. No temporal precedence of the one over the other exists. Rather, it depends on the aim of the inquiry. Source-oriented inquiry addresses itself to the biblical world as it really was, usually to some specific dimension thereof. Discourseoriented analysis, on the other hand, sets out to understand not the realities behind the text, but the text itself as a pattern of meaning and effect.

x. Syntagmatic and paradigmatic: This distinction has also been developed within the specialized field of structural linguistics under the influence of De Saussure ${ }^{44}$. However, it could also be utilized to map the process of textual interpretation. The textual structure is basically one of combinations, contrasts, and oppositions, since the elements of texts achieve meaning only in relationship. The sequence of relationships for both sender and receiver, is linear or syntagmatic. At the same time, every textual element prompts associations with other related unspoken (or "unwritten") signs. Such relationships are of a paradigmatic type.

41. Cf. e.g. the various contributions in De Moor (ed.) (1995). This discussion is regarded as important in the Dutch context, particularly because of the influence of the Amsterdam School which favours the priority of synchronical approaches (without excluding diachronical approaches). Cf. also Le Roux's description (1993) of the two ways in which the methodological discussion in the South African context developed.

42. Cf. my proposal in this regard (1996).

43. Cf. Sternberg (1985, 15ff.). Cf. also my description (1996, 208ff.) of Sternberg's contribution.

44. Cf. my discussion of these terms $(1986,19 \mathrm{ff}$.). 
xi. Tropes and topics: Those following the classical tradition in rhetorical criticism, often distinguish inter alia between tropes and topics. Tropoi refer to figures of speech and techniques of language usage. Topoi refer to the areas that serve as sources for arguments. This scheme is often augmented by a further distinction between genera (various types of address) and enthumemata (implicit arguments) ${ }^{45}$.

\section{Conclusion}

As it was stated in the introduction the pretence of this article was never to provide an exhaustive list of factors that play a role in Biblical interpretation, or of possible maps to order all these factors. The more modest aim was rather to use the list genre to provide a small glossary of often used terms and distinctions. These lists of factors and "interpretation maps" served the purpose of providing the descriptive tools in the pilot project which had the reading of the Bible by established Bible study groups consisting of ordinary readers as its focus.

45. Cf. Lawrie's description (in Conradie et al, 1995, 151ff.) of the various methodological courses rhetorical criticism can choose. 


\section{BIBLIOGRAPHY}

Beal, TK 1992. "Ideology and Intertextuality: Surplus of Meaning and Controlling the Means of Production" in DN Fewell (ed.), Reading between texts. Intertextuality and the Hebrew Bible, Louisville, Kentucky, 27-39.

Conradie, EM et al 1995. Fishing for Jonah. Various approaches to Biblical interpretation. Bellville: University of the Western Cape.

Conradie, EM \& Jonker, LC 2001. Angling for interpretation. A guide to understand the Bible better. Bellville: University of the Western Cape.

De Moor, JC (ed.) 1995. Synchronic or Diachronic? A Debate on Method in Old Testament Exegesis. OTS 34. Leiden: Brill.

Fish, S 1980. Is there a text in this class? The authority of interpretive communities. Cambridge, Massachusetts.

Jonker, LC 1986. 'n Sintakties-semantiese studie van die partisipium aktief in I Konings. University of Stellenbosch: Unpublished MA-thesis.

Jonker, LC 1996. Exclusivity and Variety. Perspectives on Multidimensional Exegesis. Kampen: Kok.

Jonker, LC 1999. "Communities of faith as texts in the process of biblical interpretation", Skrif en Kerk 20/1, 79-92.

Jonker, LC, Conradie, EM \& Botha, J 1997. Die Bybel in fokus. Leesgids vir 'n nuwe tyd. Cape Town: Lux Verbi.

Lategan, BC 1992. "Hermeneutics", ABD 3, 149-154.

Le Roux, JH 1993. A Story of two ways. Thirty years of Old Testament scholarship in South Africa. OTS.SS 2. Pretoria: Verba Vitae.

Miscall, PD 1995. "Texts, more texts, a textual reader and a textual writer", Semeia 69, 247-260.

Nielsen, K 1994. "A mainline Protestant view" in Wilson, HS (ed.), Christian fundamentalism today. Geneva, 40-52.

Robbins, VK 1996. Exploring the Texture of Texts: A Guide to Socio-Rhetorical Interpretation. Valley Forge, PA: Trinity International.

Smit, DJ 1987. Hoe verstaan ons wat ons lees? ' $n$ Dink- en werkboek oor die hermeneutiek vir predikers en studente. Cape Town: Lux Verbi.

Sternberg, M 1985. The Poetics of Biblical Narrative. Ideological Literature and the Drama of Reading. Bloomington: Indiana University.

Van Wolde, E 1990. "Van tekst via tekst naar betekenis", Tijdschrift voor Theologie 30, 333-361.

Voelz, J 1989. "Multiple signs and double texts: Elements of intertextuality" in Draisma, S (ed.), Intertextuality in Biblical writings. Essays in honour of Bas van Iersel, Kampen, 27-34.

Voelz, J 1995. "Multiple Signs, Levels of Meaning and Self as Text: Elements of Intertextuality", Semeia 69, 149-164.

West, G 1991. Biblical Hermeneutics of Liberation. Modes of reading the Bible in the South African context. Pietermaritzburg: Cluster. 